\title{
Dynamic 4D-CT Angiography for Guiding Transarterial Chemoembolization: Impact on the Reduction of Contrast Material, Operator Radiation Exposure, Catheter Consumption, and Diagnostic Confidence
}

\author{
Dynamische 4D-CT-Angiografie zur Planung der transarteriellen \\ Chemoembolisation: Einfluss auf die Kontrastmittelreduktion, die \\ Strahlenexposition des Interventionalisten, den Katheterverbrauch \\ und die Diagnosesicherheit
}

Authors

Moritz H. Albrecht, Thomas J. Vogl, Julian L. Wichmann, Simon S. Martin, Jan-Erik Scholtz, Sebastian Fischer, Renate M. Hammerstingl, Marc Harth, Nour-Eldin A. Nour-Eldin, Axel Thalhammer, Stephan Zangos, Ralf W. Bauer

Affiliation

Department of Diagnostic and Interventional Radiology,

University Hospital Frankfurt, Germany

Key words

abdomen, chemoembolization, CT, radiation safety, contrast agents

received 23.01 .2018

accepted 17.03.2018

Bibliography

DOI https://doi.org/10.1055/a-0595-7964

Published online: 2018

Fortschr Röntgenstr 2018; 190: 513-520

(c) Georg Thieme Verlag KG, Stuttgart · New York

ISSN 1438-9029

Correspondence

Prof. Thomas J. Vogl

Institut für Diagnostische und Interventionelle Radiologie,

J. W. Goethe-Universität Frankfurt, Theodor-Stern Kai 7,

60596 Frankfurt, Germany

Tel.: ++ 49/69/6301-72 77

Fax: ++49/69/63 01-7258

T.vogl@em.uni-frankfurt.de

\section{ZUSAMMENFASSUNG}

Zielsetzung Ziel dieser Studie war die Analyse der Auswirkungen einer dynamischen vierdimensionalen CT-Angiografie (4D-CTA) für die Planung transarterieller Chemoembolisationen (TACE) im Hinblick auf Kontrastmittelverbrauch, Strahlenexposition für den Interventionalisten, Katheterverbrauch und diagnostische Sicherheit.

Material und Methoden Neunundzwanzig Patienten (20 Männer; mittleres Alter, 65,7 \pm 11,5 Jahre) mit malignen Lebertumoren unterzogen sich einer 4D-CTA Untersuchung vor der ersten TACE. Zeitlich aufgelöste Volumenrekonstruktionen (VRT), Maximumintensitätsprojektionen (MIP) und multiplanare Reformatierungen (MPR) wurden rekonstruiert um eine direkte selektive Sondierung der tumorversorgenden Arterie zu ermöglichen ohne Durchführung einer vorhergehenden konventionellen digitalen Subtraktionsangiografie (DSA). Eine weitere Kohorte mit 29 Patienten, in der eine Standard-TACE durchgeführt wurde diente als Kontrollgruppe (16 Männer; mittleres Alter, 69,4 \pm 13,9 Jahre). Die Menge des verabreichten Kontrastmittels, die Strahlenbelastung des Radiologen und der Katheterverbrauch während der TACE wurden verglichen. Zwei Radiologen bewerteten die diagnostische Sicherheit für den Ausschluss einer Pfortaderthrombose.

Ergebnisse 4D-CTA TACE führte zu einer signifikanten Reduktion des benötigten Kontrastmittels im Vergleich zur traditionellen TACE (-61,0 ml / -66,3\% intraarteriell; $-12,8 \mathrm{ml} /-13,8 \%$ insgesamt; $\mathrm{P}<0,001)$. Das Dosisflächenprodukt, welches die Strahlenexposition des Radiologen während der Intervention anzeigt, wurde um 50,5\% reduziert $(\mathrm{P}<0,001)$. Im Durchschnitt wurden 0,7 weniger Katheter verwendet $(P=0,063)$ wenn Daten einer 4D-CTA zur Verfügung standen. Die diagnostische Sicherheit für den Ausschluss einer Pfortaderthrombose wurde durch die 4D-CTA im Vergleich zu herkömmlichen DSA-Bildern signifikant erhöht (Werte, 3,9 bzw. 2,4; $\mathrm{P}<0,001$ ).

Schlussfolgerung Die dynamisches 4D-CTA ermöglicht die Durchführung einer TACE mit signifikant geringerer Kontrastmittelapplikation und Strahlenexposition des interventionellen Radiologen und erhöht die diagnostische Sicherheit für den Ausschluss einer Pfortaderthrombose.

\section{Kernaussagen}

- 4D-CTA Untersuchungen vor TACE ermöglichen eine deutliche Kontrastmittelreduktion.

- Der intraarterielle Anteil des Kontrastmittels wird dabei um zwei Drittel reduziert. 
- Das Risiko einer Kontrastmittel-induzierten Nephropathie könnte gesenkt werden durch die 4D-CTA TACE Technik.

- 4D-CTA vor TACE führt zu einer geringeren Strahlenbelastung für den Radiologen.

- 4D-CTA Portografie Bilder ermöglicht ein verbesserte diagnostische Konfidenz als konventionelle DSA Aufnahmen.

\section{ABSTRACT}

Purpose This study was carried out to investigate the impact of abdominal dynamic four-dimensional CT angiography (4D-CTA) for guiding transarterial chemoembolization (TACE) on the amount of contrast material used, operator radiation exposure, catheter consumption, and diagnostic confidence.

Materials and Methods Written consent was waived for this IRB-approved retrospective study. 29 patients (20 men; mean age: $65.7 \pm 11.5$ years) with malignant liver lesions underwent 4D-CTA, prior to initial TACE. Time-resolved volume-rendering technique (VRT), maximum-intensity projection (MIP), and multiplanar reconstruction (MPR) series were reconstructed, enabling a direct selective catheterization of the tumorsupplying artery without prior conventional digital subtraction angiography (DSA). 29 patients (16 men; mean age: $69.4 \pm 13.9$ ) who underwent traditional TACE served as the control group. The amount of administered contrast media, operator radiation exposure, and catheter consumption during TACE were compared. Two radiologists assessed diagnostic confidence in the exclusion of portal vein thrombosis.

Results 4D-CTA TACE resulted in a significant reduction in the amount of contrast media used, compared to traditional TACE (-61.0 ml/ -66.3\% intra-arterial, $-12.8 \mathrm{ml} /-13.8 \%$ overall; $\mathrm{P}<0.001)$. The dose-area product indicating operator radiation exposure during intervention was reduced by $50.5 \%$ $(P<0.001)$, and 0.7 fewer catheters on average were used $(P=0.063)$, while 4D-CTA data was available to guide TACE. Diagnostic confidence in the exclusion of portal vein thrombosis was significantly enhanced by 4D-CTA, compared to traditional DSA images (scores, 3.9 and 2.4, respectively; $\mathrm{P}<0.001)$.

Conclusion Dynamic 4D-CTA enables TACE with a substantially reduced amount of contrast material, decreases operator radiation exposure, and increases diagnostic confidence in the exclusion of portal vein thrombosis.

\section{Key points}

- 4D-CTA prior to TACE decreases the amount of utilized contrast material.

- The intra-arterial fraction of contrast media can be reduced by two-thirds.

- The risk of CIN may be decreased by means of 4D-CTA TACE.

- Operator radiation exposure is lower using 4D-CTA for guiding TACE.

- 4D-CTA portography allows for a higher diagnostic confidence than conventional DSA images.

\section{Citation Format}

- Albrecht MH, Vogl TJ, Wichmann JL et al. Dynamic 4D-CT Angiography for Guiding Transarterial Chemoembolization: Impact on the Reduction of Contrast Material, Operator Radiation Exposure, Catheter Consumption, and Diagnostic Confidence. Fortschr Röntgenstr 2018; 190: 513-520

\section{Introduction}

Transarterial chemoembolization (TACE) is a well-established treatment option for patients with malignant liver tumors [1 - 5] and has been shown to enable both an improved overall survival in a palliative setting and "bridging" prior to curative liver transplantation or hepatectomy $[4,6-8]$.

During the first TACE, an extensive catheter angiography is usually performed for the abdominal aorta and its upper abdominal braches, in particular the coeliac trunk and the superior mesenteric artery, in order to visualize the arterial blood supply of the liver and the intrahepatic tumor, as well as to exclude anatomical variants or possible arterial stenosis $[4,9]$. Subsequently, thrombosis of the portal vein is excluded by evaluating the contrast material flow through the spleen or the splanchnic territory to the portal vein - the so-called indirect portography [2, 9]. As the image quality and contrast of these conventional angiography (DSA) images may be limited and depend on the interventionalist's experience and the patient's anatomy, catheters may have to be changed several times during the intervention. In complex cases, this may increase material costs, administered contrast media volume, and operator radiation exposure due to scattered radiation $[10,11]$. In this context, a reduction in contrast material volume might improve patients' safety [12 - 14], since it has been frequently stipulated that an increased iodine load may be associated with a higher risk of contrast-induced nephropathy (CIN) $[12,15-18]$, especially when administered intra-arterially rather than intra-venously $[12,16,18-20]$.

For these reasons, we performed a planning dynamic CT angiography (4D-CTA) of the upper abdomen, providing information on the arterial anatomy, blood tumor supply, and portal vein patency prior to TACE. After the selection of the appropriate catheter, a direct selective or super-selective catheterization of the tumor-supplying artery was performed subsequently without prior conventional DSA.

Thus, the aim of this study was to investigate the impact of this 4D-CTA TACE technique on the contrast material utilized, operator radiation exposure, catheter consumption, and diagnostic confidence in the exclusion of portal vein thrombosis. 


\section{Materials and Methods}

\section{Patients and study design}

Our local institutional review board endorsed this retrospective study with a waiver of written consent. From October 2014, we changed the TACE workflow in our institution by including a 4D-CTA prior to intervention, instead of stepwise extensive DSA examinations of the aorta and its branches. The inclusion criteria were: no previous TACE or DSA of the upper abdomen; absence of portal vein thrombosis; bilirubin $<2.0 \mathrm{mg} / \mathrm{dl}$; thrombocyte count $>50 / \mu$; INR < 1.5; eGFR > $45 \mathrm{ml} / \mathrm{min}$. Our initial study population consisted of 35 patients, from which we had to exclude three patients with elevated bilirubin values. Another three patients had to be excluded because they were unable to hold their breath sufficiently long for the procedure due to accompanying cardiopulmonary diseases. Thus, our final study cohort consisted of 29 patients ( 20 men; mean age, $65.7 \pm 11.5$ years). Another 29 randomly selected patients (16 men; mean age, 69.4 \pm 13.9 ), who underwent the traditional TACE workflow before October 2014, served as the control group. Individual patient data are summarized in $>$ Table 1.

\section{Dynamic 4D-CTA image acquisition}

Dynamic 4D-CTA examinations were conducted using a 192-slice dual-source CT scanner (Somatom Force, Siemens Healthcare, Forchheim, Germany). In shuttle-mode, a z-axis coverage of $17.6 \mathrm{~cm}$ with a temporal resolution of $1.5 \mathrm{~s}$ was obtained to have covered the whole liver, the coeliac trunk and the superior mesenteric artery alongside their relevant branches. Patients were placed in a supine position and the scan started $8 \mathrm{~s}$ after initiation of contrast material injection. On the average, $48.2 \pm 3.8 \mathrm{ml}$ (range, $40-50 \mathrm{ml}$ ) of contrast media (iopamidol, Imeron 400 , Bracco, Milan, Italy) were administered via a vein of the antecubital fossa at a flow rate of $5 \mathrm{ml} / \mathrm{s}$, followed by a $50 \mathrm{ml}$ saline flush. The first 20 scans were acquired with a cycle time of $1.5 \mathrm{~s}$ and the last 5 scans with $3 \mathrm{~s}$, resulting in a total examination time of $45 \mathrm{~s}$ for each patient. The patients were instructed to hold their breath after normal moderate inspiration for as long as possible and to resume shallow breathing when the breath hold was no longer possible. Other settings were as follows: tube voltage $80 \mathrm{kV}$; tube current-time-product $100 \mathrm{mAs}$; collimation $48 \times 1.2 \mathrm{~mm}$. As no $\mathrm{mA}$-modulation was used, a fixed $\mathrm{CTDI}_{\mathrm{vol}}$ of $48.9 \mathrm{mGy}$ and a DLP of 961 mGycm were measured in each patient.

\section{Post-processing of 4D-CTA data and TACE planning}

Post-processing of dynamic 4D-CTA data was performed on a commercially available workstation (syngo.via, version VA30A, Siemens) by using the "CT dynamic angio" application. After an automatic motion correction had been applied, the time-resolved image stacks of the entire data set or at any arbitrary time point of the $45 \mathrm{~s}$ long series were reconstructed as dynamic multiplanar reformate (MPR), volume-rendering technique (VRT) and maximum-intensity projection (MIP) series. These reconstructions were calculated in anterior-posterior direction, to give an overview of the vascular anatomy and in lateral horizontal view, to
- Table 1 Patient characteristics.

- Tab. 1 Patientencharakteristika.

\begin{tabular}{|c|c|c|c|}
\hline & & $\begin{array}{l}\text { 4D-CTA } \\
\text { group }\end{array}$ & $\begin{array}{l}\text { Control } \\
\text { group }\end{array}$ \\
\hline \multirow[t]{2}{*}{ Sex } & Male & 20 & 16 \\
\hline & Female & 9 & 13 \\
\hline \multicolumn{2}{|c|}{$\begin{array}{l}\text { Age, mean } \pm \text { standard deviation (SD) } \\
\text { Body-mass index [] }\end{array}$} & $\begin{array}{l}65.7 \pm 11.5 \\
{[25.8 \pm 3.5]}\end{array}$ & $\begin{array}{l}69.4 \pm 13.9 \\
{[24.3 \pm 2.7]}\end{array}$ \\
\hline \multirow[t]{2}{*}{$\begin{array}{l}\text { Primary liver } \\
\text { cancer }\end{array}$} & $\begin{array}{l}\text { HCC (hepatocellular } \\
\text { carcinoma) }\end{array}$ & 12 & 15 \\
\hline & $\begin{array}{l}\text { CCC (cholangiocellular } \\
\text { carcinoma) }\end{array}$ & 2 & 3 \\
\hline \multirow{4}{*}{$\begin{array}{l}\text { Metastases } \\
\text { from }\end{array}$} & Colorectal cancer & 9 & 6 \\
\hline & Breast cancer & 4 & 5 \\
\hline & Esophageal cancer & 1 & 0 \\
\hline & Neuroendocrine tumor & 1 & 0 \\
\hline
\end{tabular}

depict the angle between the coelic trunk and aorta, which was considered to be relevant for catheter selection. Additional snapshot images were saved from various angles to depict individual's vascular anatomy. Furthermore, the portal vein perfusion was assessed on MPR and MIP images to exclude thrombosis. Window settings were carefully altered, to exclude overlying liver and soft tissue which might complicate accurate diagnosis of vascular anatomy and portal vein patency. Patients underwent TACE within 3 days after the 4D-CTA exam.

\section{TACE procedure}

For both cohorts, TACE treatments were performed by a radiologist having more than 25 years of experience (T.J. V.) in 24 cases and by a radiologist with more than 7 years of experience (R. W. B.) in 5 cases. A transfemoral access was used in all cases with a $5 \mathrm{~F}$ sheath (Glidesheath, Terumo, Tokyo, Japan). Puncture of the common femoral artery was performed with a steel needle after local anesthesia.

In the control group undergoing standard TACE, an initial overview DSA with 2 frames/s of the abdominal aorta after administration of n-butylscopolamine was performed with a $5 \mathrm{~F}$ pigtail catheter (Boston Scientific, Marlborough, MA) and a power injector with $30 \mathrm{ml}$ of contrast material (iodixanol, Visipaque 320, GE Healthcare, Little Chalfont, United Kingdom) at a flow rate of $15 \mathrm{ml} / \mathrm{s}$. Subsequently, a selective catheterization of the superior mesenteric artery was performed with a $5 \mathrm{~F}$ sidewinder or cobra catheter (Terumo) and DSA images (2 frames/s) of the splanchnic territory, including the indirect portography were acquired with another $30 \mathrm{ml}$ of contrast material injected at a flow of $3 \mathrm{ml} / \mathrm{s}$. Finally, the coeliac trunc was intubated with the same catheter and a DSA series (2 frames/s) was acquired again, with a power injector and $15 \mathrm{ml}$ of contrast material at a flow rate of $3 \mathrm{ml} / \mathrm{s}$.

In the 4D-CTA TACE study group, after dynamic VRT, MIP, and MPR series were analyzed, a direct selective intubation of the 
tumor-supplying artery was performed by the pre-selected catheter under fluoroscopy guidance without further DSA images. However, small amounts of contrast material were injected manually for position control of the catheter.

For chemoembolization in both cohorts, the tumor-supplying artery was further super-selectively intubated with a coaxial micro catheter (Progreat, Terumo) if necessary. Under fluoroscopy guidance, with manual injection of 5-10 ml diluted contrast material, the chemoembolization was performed as selectively as possible. For embolization, lipiodol (lipiodol ultra-fluid, Guerbet, Villepinte, France) was used in varying amounts until stasis of the blood flow was achieved. Cytostatic drugs varied according to tumor entity. After the catheters and sheath were removed, the puncture site was sealed by the use of a closure device (Angioseal, St. Jude Medical, St. Paul, MN).

In all TACE procedures, the fluoroscopy time was recorded, as this parameter was empirically considered to be an indicator for the complexity of the TACE performed.

\section{Subjective analysis of portography images}

Two blinded radiologists with more than 4 years of experience (J-E. S. and S. F.) in CT imaging and angiography performed an additional separate image analysis. The 4D-CTA MIP series and the conventional DSA portography images were reviewed independently and in random order. Visualization of portal vein perfusion and subsequent diagnostic confidence in the exclusion of portal vein thrombosis was rated using five-point Likert scales ( 1 = insufficient contrast to assess portal vein perfusion and resulting low diagnostic confidence; 2 = limited contrast to assess portal vein perfusion; 3 = acceptable contrast in portal vein; 4 = sufficient contrast in portal vein; 5 = excellent visualization of portal vein and its branches with a resulting high diagnostic confidence).

\section{Statistical Analysis}

Data were expressed as mean values \pm one-fold standard deviation (SD). Commercially available software was used for statistical data analysis (MedCalc Statistical Software version 12.7.2, MedCalc Software bvba, Ostend, Belgium). The normality of the data distribution was assessed using the Kolmogoroff-Smirnoff test. Data showing a Gaussian distribution were evaluated by means of an unpaired student's t-test. The Mann-Whitney test was applied, where no normal data distribution was present.

Inter-rater agreement was analyzed by means of Cohen's kappa (к) analysis, and the coefficients were interpreted as follows: $\kappa<0.20$ = slight agreement; $\kappa: 0.21-0.40$ = fair agreement; к: $0.41-0.60=$ moderate agreement; $\mathrm{\kappa}: 0.61-0.80=$ substantial agreement; $\mathrm{k:} 0.81-1.0=$ almost perfect agreement. A P-value less than 0.05 was considered to indicate a significant result for the tests that were performed.

\section{Results}

All 4D-CTA scans were of diagnostic value and were performed without occurrence of relevant motion artifacts. No complications
- Table 2 Target values from the 4D-CTA study and traditional TACE cohort.

- Tab. 2 Zielwerte der 4D-CTA-Studie und der traditionellen TACEKohorte.

\begin{tabular}{|c|c|c|c|}
\hline \multicolumn{2}{|l|}{ Parameter } & 4D-CTA TACE & Standard TACE \\
\hline \multirow{2}{*}{$\begin{array}{l}\text { Contrast } \\
\text { media }(\mathrm{ml})\end{array}$} & Overall & $78.9 \pm 16.2^{1}$ & $92.0 \pm 10$ \\
\hline & Arterial amount & $30.6 \pm 16.9^{1}$ & $92.0 \pm 10$ \\
\hline \multicolumn{2}{|c|}{$\begin{array}{l}\text { Dose-area product during TACE } \\
\text { intervention }\left(\mu G y m^{2}\right)\end{array}$} & $\begin{array}{l}1121.2 \\
\pm 1337.5^{1}\end{array}$ & $\begin{array}{l}2268.1 \\
\pm 1145.1\end{array}$ \\
\hline \multicolumn{2}{|c|}{ Catheters used } & $2.4 \pm 0.8$ & $3.1 \pm 0.9$ \\
\hline \multicolumn{2}{|c|}{ Time of fluoroscopy (minutes) } & $3.4 \pm 1.8$ & $3.5 \pm 1.9$ \\
\hline \multicolumn{2}{|c|}{$\begin{array}{l}\text { Score from subjective portography } \\
\text { analysis }\end{array}$} & $3.9 \pm 0.7^{1}$ & $2.4 \pm 0.7$ \\
\hline \multicolumn{4}{|c|}{$\begin{array}{l}\text { indicates statistical significance. } \\
\text { kennzeichnet eine statistische Signifikanz. }\end{array}$} \\
\hline
\end{tabular}

occurred, neither during 4D-CTA image acquisition nor during TACE in all the patients. Table $\mathbf{2}$ gives an overview on the target values assessed in our study.

\section{Contrast media}

In the control group undergoing traditional TACE, the amount of overall administered contrast media was $92.0 \pm 10.0 \mathrm{ml}$ (range, $75-120 \mathrm{ml}$ ), which was inherently injected intra-arterially in all.

In the study cohort with 4D-CTA series for guiding TACE, 78.9 $\pm 16.2 \mathrm{ml}$ (range, $60-130 \mathrm{ml}$ ) of contrast media were administered overall, which was $13.9 \%$ less compared to the control group $(P<0.001)$. Of that total amount, $30.6 \pm 16.9 \mathrm{ml}$ (range, $10-80 \mathrm{ml}$ ) were administered intra-arterially, which was $66.3 \%$ less in comparison with the traditional TACE cohort $(P<0.001)$.

\section{Operator radiation exposure}

With regard to the control group, the patient dose-area-product in the immediate presence of the radiologist during TACE amounted to $2268.1 \pm 1145.1 \mu \mathrm{Gym}^{2}$ (range, 613.1 - $5571.8 \mu \mathrm{Gym}^{2}$ ).

In the 4D-CTA study group, the patient radiation exposure during TACE with the radiologist in the angio suite was 1121.2 $\pm 1337.5 \mu \mathrm{Gym}^{2}$ (range, $64-6209 \mu \mathrm{Gym}^{2}$ ) and thus, operator exposure due to scattered radiation could be reduced by $50.5 \%$ $(P<0.001)$, when 4D-CTA series were available to guide TACE.

\section{Catheter consumption}

In total, $3.1 \pm 0.9$ catheters (range, $2-5$ ) were used for conventional TACE. In the 4D-CTA TACE group, $2.4 \pm 0.8$ catheters were used on average (range, $1-4$ ). However, this mean reduction of 0.7 catheters ( $22.5 \%$ ) by using 4D-CTA was not statistically significant $(P=0.063)$. 


\section{Time of fluoroscopy}

There was no significant difference $(P=0.578)$ regarding time of fluoroscopy between the control (3.5 \pm 1.9 minutes; range, $0.9-8.6)$ and the 4D-CTA TACE group (3.4 \pm 1.8 minutes; range, $1.4-8.3$ ).

\section{Subjective analysis of portography images}

The cumulative scores regarding the assessment of portal vein perfusion and diagnostic confidence in the exclusion of portal vein thrombosis from the two radiologists were superior $(\mathrm{P}<0.001)$ for the 4D-CTA study group (score, $3.9 \pm 0.7$; range, $3-5$ ) than standard portography images (score, $2.4 \pm 0.7$; range, $1-4)$. There was a substantial agreement of both reviewers for the standard $(\mathrm{K}=0.74, \mathrm{P}<0.001)$ and the $4 \mathrm{D}-\mathrm{CTA}$ cohort $(K=0.68, P<0.001)$.

\section{Discussion}

This study aimed at comparing the 4D-CTA TACE to traditional TACE with purely conventional DSA images with regard to administered contrast material, operator radiation exposure, catheter consumption and diagnostic confidence in the exclusion of portal vein thrombosis.

Our data indicates that the dynamic 4D-CTA image acquisition for guiding TACE leads to substantially reduced amount of intraarterial and overall contrast material used, decreases operator radiation exposure during intervention, and enables a superior assessment of portal vein perfusion than conventional portography images. We believe that these potential benefits may outweigh the effort of an additional CT exam prior to TACE.

Assessing the administered contrast material volume for both cohorts was the first priority of our study, as the prevention of CIN remains an issue of great current interest $[12,17,18,20]$. As we demonstrated that 4D-CTA TACE can be performed with twothirds less arterially administered contrast media volume in comparison to the standard TACE procedure, we presume that this technique might decrease the risk of CIN and may enable TACE treatment for patients with reduced renal function, although our study did not aim at investigating this end point. It also may facilitate an increased frequency of TACE procedures when a present renal impairment limits therapy options.

Although the pathophysiological mechanism of CIN is not sufficiently clarified yet [21], the vast majority of clinical studies describe a lower incidence of CIN in patients receiving contrast material intra-venously rather than intra-arterially [22, 23]. In this regard, not so much osmolality as higher viscosity during intra-arterial injection was presumed to be a potential explanation $[16,18]$. On the contrary, in a recent study, the incidence of CIN following TACE of HCC seemed to be comparable to that after intra-venous contrast media administration [12]. However, as long as this issue remains a topic on the ongoing controversial investigation, we consider especially a reduction of the intra-arterial fraction of administered contrast media as desirable, to enhance patient safety and minimize the risk of CIN. In routine clinical practice, radiologists and other treating clinicians should be aware of the option of optimizing contrast material consump-

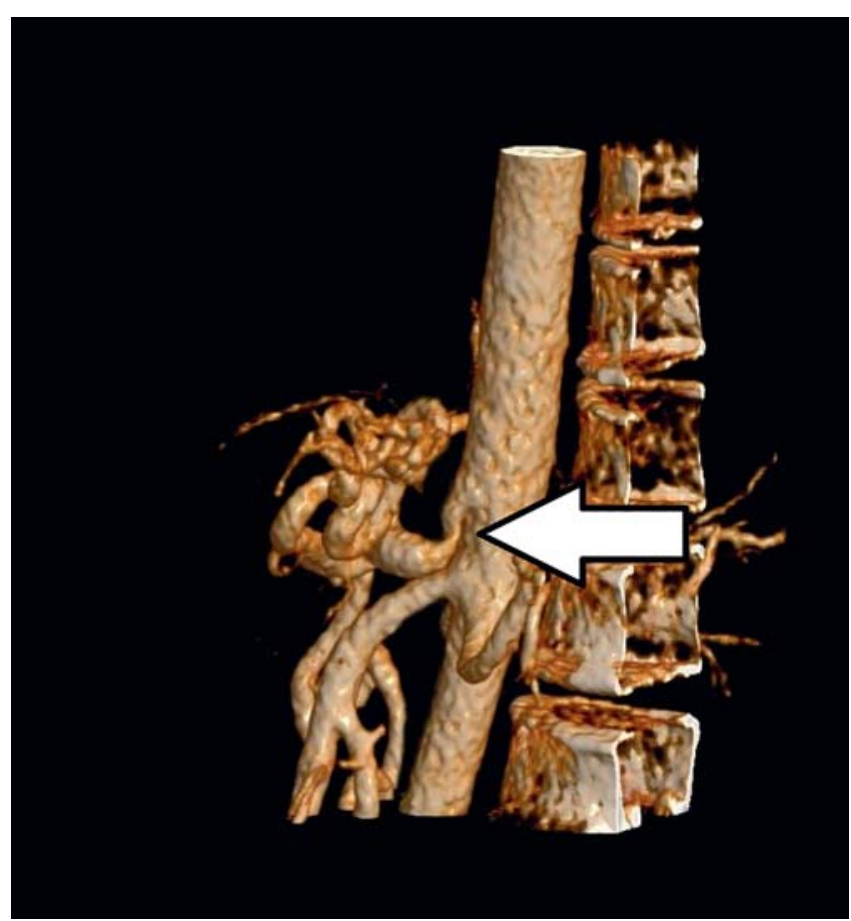

- Fig. 1 Prior to transarterial chemoembolization (TACE), fourdimensional $C T$ angiography (4D-CTA) volume-rendering technique (VRT) images of a 73-year-old male patient with colorectal liver metastases were reconstructed (seconds after initiation of contrast injection: $22.5 \mathrm{~s}$ ). The lateral view of the reconstructed VRT series reveals a steep origin of the celiac trunk, possibly facilitating catheter selection. Furthermore, stenosis of the celiac trunk is also depicted (arrow).

- Abb. 1 Vor transarterieller Chemoembolisation (TACE) wurden vierdimensionale CT-Angiographie (4D-CTA) Volumen-RenderingTechnik (VRT) Bilder eines 73-jährigen Patienten mit kolorektalen Lebermetastasen rekonstruiert (Sekunden nach Beginn der Kontrastmittelgabe: 22.5 s). Die laterale Ansicht der VRT Rekonstruktion zeigt einen steilen Ursprung der Truncus coeliacus, was möglicherweise die Katheterauswahl erleichtert. Außerdem ist eine Stenose des Truncus coeliacus dargestellt (Pfeil).

tion by using the 4D-CTA TACE technique. Concomitantly, gaining experience with this workflow in departments where TACE is routinely performed will be important to realize an effective reduction of contrast media.

Radiation dose caused by scattered $x$-rays during conventional angiography remains an unsolved problem addressed by numerous investigations $[10,11,24]$. In our study, we showed that by means of 4D-CTA, a large part of conventional angiography leading to increased radiation exposure for the radiologist during TACE may be evitable, as dose-area-product and thus, scattered radiation could be reduced by half compared to traditional TACE. We assume that this may be another effective strategy in order to reduce operator radiation dose in addition to maintaining the greatest possible distance to the photon-emitting tube and the use of $\mathrm{x}$-ray protective equipment.

Furthermore, we assumed that a pre-procedural planning 4D-CTA allowing for a comprehensive 4D imaging from different angles may lead to a reduced catheter consumption, which could 

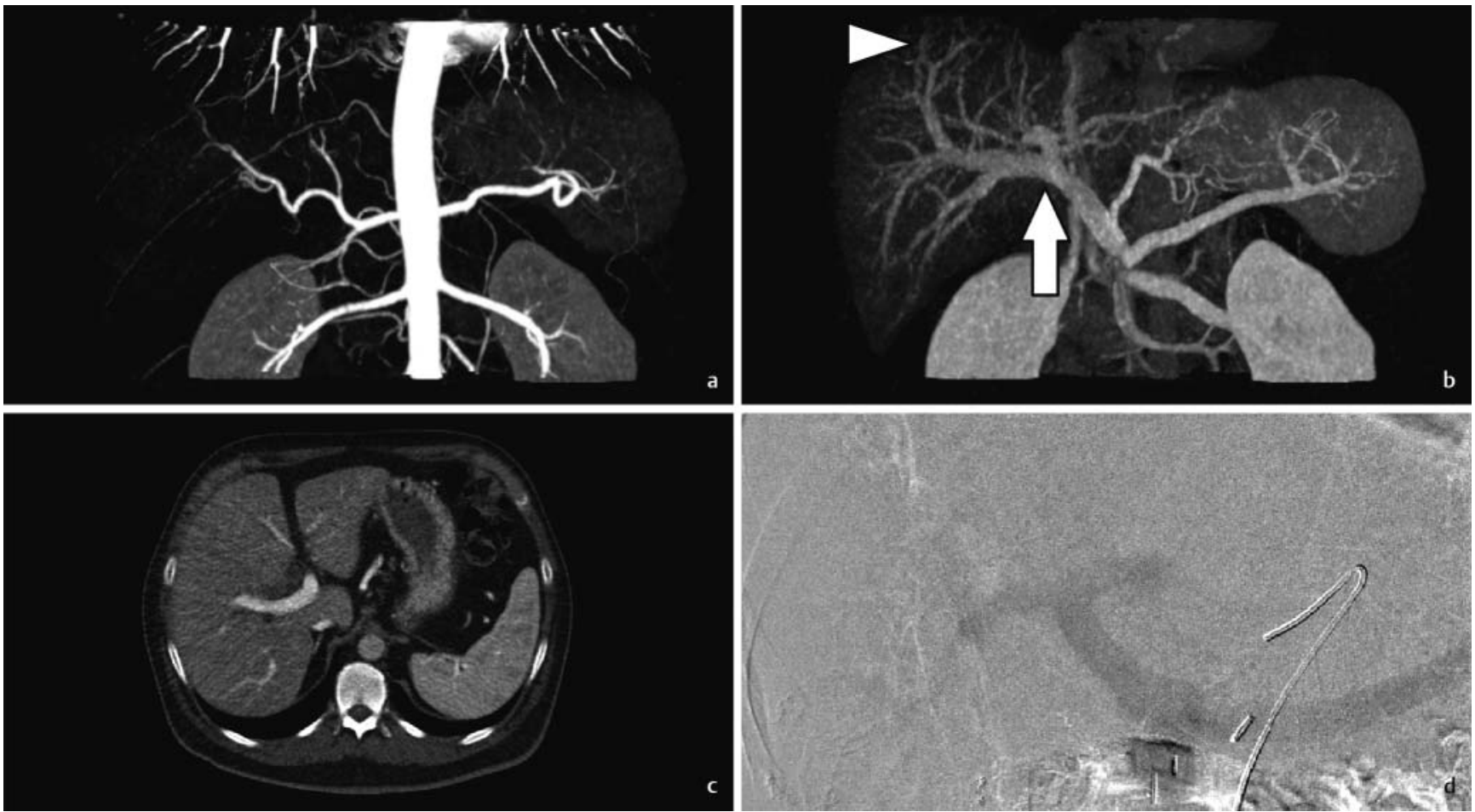

- Fig. 2 a-d Coronary 4D-CTA maximum-intensity projection (MIP) reconstructions from a 54-year-old female patient (seconds after initiation of contrast injection: a 18s; b $41 \mathrm{~s}$ ) reveal distinct contrast conditions in the central portal vein (arrow) and also its sub-segmental branches (arrowhead). Axial 4D-CTA multiplanar reconstruction (MPR) series may additionally be analyzed for the assessment of portal vein perfusion (c 41 seconds after the initiation of contrast injection). Furthermore, 4D-CTA MIP series ensure the inclusion of maximum portal-venous attenuation b. On the contrary, even in conventional angiographic portography images with relatively high image quality and contrast (d another patient), the evaluation of portal vein perfusion in segmental distant branches is limited.

- Abb. 2 a-d Koronare 4D-CTA Maximumintensitätsprojektionen (MIP) einer 54-jährigen Patientin (Sekunden nach Beginn der Kontrastmittelgabe: a, 18s; b, 41 s) weisen sehr gute Kontrastverhältnisse in der zentralen Pfortader (Pfeil) und auch in deren subsegmentalen Ästen (Pfeilspitze) auf. Für die Beurteilung der Pfortaderperfusion können zusätzlich axiale 4D-CTA multiplanare Rekonstruktionen (MPR) analysiert werden (c, 41 Sekunden nach Beginn der Kontrastmittelinjektion). Darüber hinaus gewährleisten die 4D-CTA MIP-Serien eine sehr gute portalvenöse Kontrastierung b. Im Gegensatz dazu kann selbst bei herkömmlichen angiografischen portografischen Bildern mit relativ hoher Bildqualität und hohem Kontrast (d, ein anderer Patient) die Beurteilung der Pfortaderperfusion in segmentalen Ästen erschwert sein.

ultimately result in a reduction of material costs. Although 4D-CTA TACE was performed using almost a quarter less catheters on average compared to standard TACE, this difference was not significant. Nevertheless, the issue of optimizing catheter selection using 4D-CTA in order to reduce material costs should be subject to future investigation with larger patient cohorts with dedicated, not merely overall analyzes of catheter usage. How 4D-CTA may facilitate catheter selection is shown in > Fig. $\mathbf{1}$.

Importantly, our results showed, that 4D-CTA increases diagnostic confidence in the exclusion of portal vein thrombosis $(\triangleright$ Fig. 2a-d). As portal vein thrombosis constitutes a contraindication for TACE [4], 4D-CTA MIP and MPR images might increase patient safety due to a more accurate assessment.

Besides limiting factors like adipositas, ascites, portocaval collateral circulation and mandatory patient cooperation, conventional DSA portography requires optimal timing during image acquisition, which depends strongly on the radiologist's experience ( $\triangleright$ Fig. $\mathbf{2 d}$ ). As a result, portal-venous contrast is frequently limited. On the contrary, 4D-CTA portography ensures due to the inclusion of multiple time points, an image of sufficient contrast in both the central portal vein and its peripheral branches ( $\triangleright$ Fig. 2b). This advantage of optimal contrast inclusion, which is independent of the examiner, also applies for arterial 4D-CTA images ( $\triangleright$ Fig. 2a), demonstrating a substantial difference to normal CTA images, where the time point of optimal arterial and portal-venous contrast conditions might easily be missed. However, future research is warranted to analyze if $4 D-C T A$ may indeed be superior for TACE planning purposes compared to standard bi- or tri-phasic CT in combination with standard ultrasound exams for arterial visualization and the assessment of portal vein perfusion. On the contrary, the fact that acquisition of dyamic data by means of 4D-CTA may allow for analyzing additional perfusion characterstics and monitoring treatment response of malignant liver lesions may be in favor of 4D-CTA.

As none of the patients undergoing 4D-CTA TACE had any complications, we demonstrated that performing TACE by direct catheterization of the coelic trunk following 4D-CTA is safe and feasible ( $\triangleright$ Fig. $3 a-c)$.

Analyzing the fluoroscopy time is essential, when assessing comparability of our results from the standard and 4D-CTA TACE 

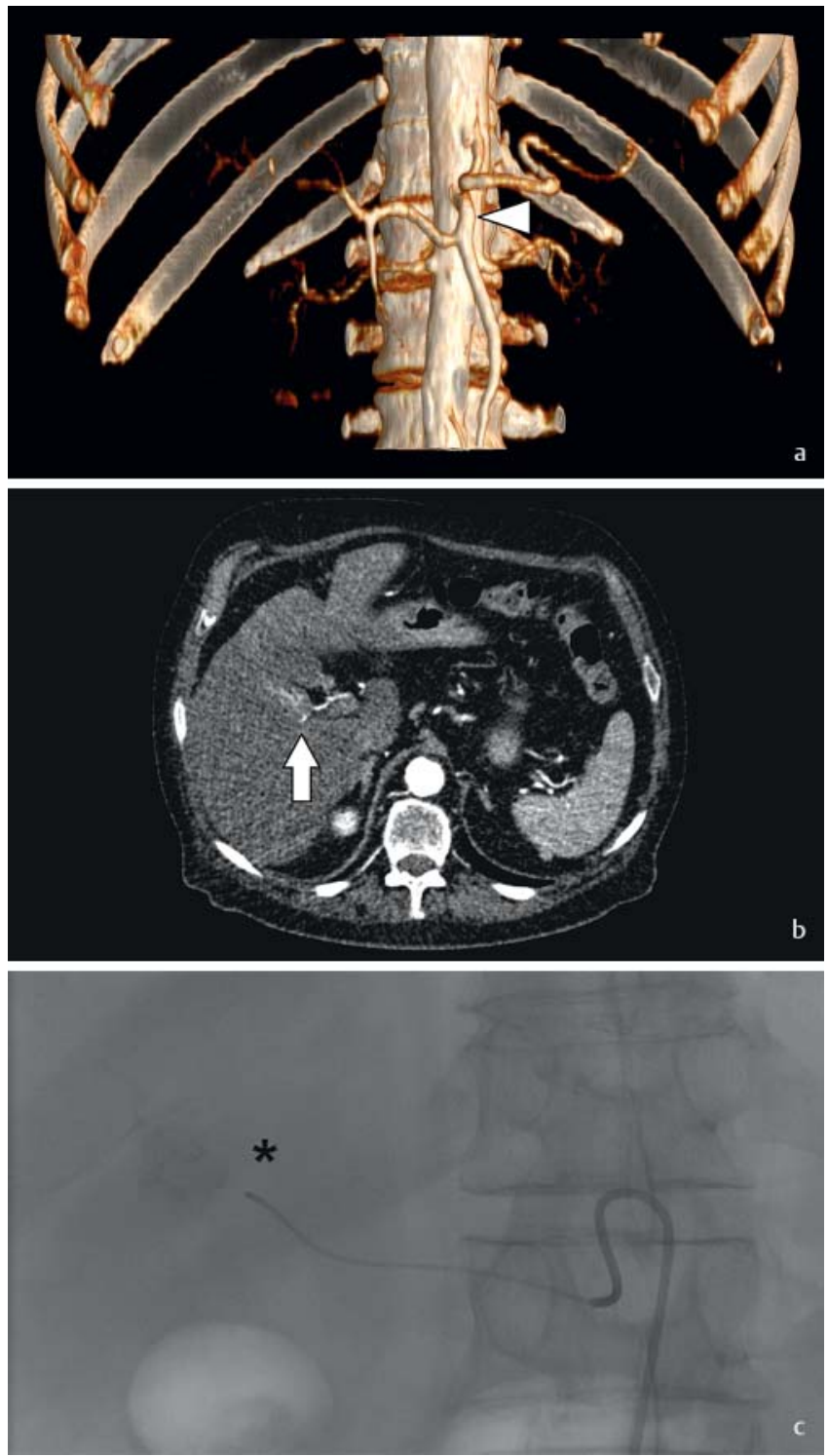

- Fig. 3 a-c Images obtained during 4D-CTA TACE of a 70-year-old male patient with multifocal hepatocellular carcinoma (HCC) (seconds after initiation of contrast injection: a 19.5s; b 21 s). The reconstructed dynamic VRT of 4D-CTA a visualizes that the common hepatic artery arises from the superior mesenteric artery (hepatomesenteric trunk, arrowhead). Axial MPR images b depict the tumor-feeding artery posteriorly adjacent to an HCC nodule in liver segment 5 (arrow), allowing for a direct super-selective TACE without additional prior angiography of the aorta. Subsequently, a high degree of lipiodol uptake by the target tumor was achieved which appears well circumscribed (c asterisk).

- Abb. 3 a-c 4D-CTA TACE eines 70-jährigen männlichen Patienten mit multifokalem hepatozellulärem Karzinom (HCC) (Sekunden nach Beginn der Kontrastmittelinjektion: a, 19,5s; b, 21 s). Die rekonstruierten dynamischen VRT-4D-CTA Bilder a zeigen, dass die A. hepatica communis aus der A. mesenterica superior (Truncus hepatomesentericus, Pfeilspitze) entspringt. Axiale MPR-Bilder b zeigen die tumorversorgende Arterie dorsal eines HCC-Knotens im Lebersegment 5 (Pfeil), was eine direkte superselektive TACE ohne zusätzliche Angiografie der Aorta ermöglicht. Dabei wurde eine sehr gute Lipiodolspeicherung im Zieltumor erreicht, der sich sehr gut abgrenzen lässt (c, Asterisk). groups. As the fluoroscopic images are normally used for catheter navigation and orientation during angiography, increasing fluoroscopy times empirically indicate a more complex intervention. Because there was no significant difference between both cohorts, complexity of TACE interventions included in our study seems to be comparable. On the other hand, one could argue about the observation that 4D-CTA did not translate into a reduced fluoroscopy time. One potential explanation may be that the interventionalists were inexperienced at the time-point of conducting the novel TACE workflow. We hypothesize that an enhanced experience might lead to reduced fluoroscopy times in the future.

As this investigation represents our initial experience with the 4D-CTA TACE workflow, we expect further improvements of our protocol used for the purpose of planning and guiding TACE in the future. In particular, we assume that protocol optimization with fewer scans might allow for a further reduction of patient radiation exposure. As recent studies investigating time-resolved 4D-CTA did not explicitly focus on subsequent intra-arterial catheterization $[25,26]$, we chose for safety reasons a total of 25 scans over a time range of $45 \mathrm{~s}$, to ensure the inclusion of arterial peak blood flow and also optimal portal-venous contrast. However, as only in 14 cases of our 4D-CTA study population the whole data set of $45 \mathrm{~s}$ was used for reconstruction of 4D-CTA series, a shortened protocol for TACE planning would be desirable, while maintaining sufficient diagnostic information in regard to liver blood supply and portal vein patency. Furthermore, future studies might reveal advantages of the inclusion of 4D-CTA for chemoembolization of other anatomical regions, for example, lung metastases, or interventions other than TACE.

Our study has several inherent limitations that should be addressed. First, our study cohort was relatively small and represents our initial experience with a new workflow. Further research will be necessary to re-evaluate our findings with a special focus on patient safety. Second, our control group of 29 patients who underwent standard TACE might have exhibit more distinct variations regarding the target variables than the average of a larger patient cohort. Last and by far most importantly, as we focused on the fraction of radiation exposure causing scattered radiation that affects interventional radiologists and in-room medical staff, we did not assess overall patients' radiation dose during 4D-TACE. As a cumulative retrospective calculation of radiation exposure from CT and conventional angiographic imaging is not adequately possible, this could be addressed in further phantom studies using $\mathrm{x}$-ray dosimeters.

In conclusion, dynamic 4D-CTA facilitates TACE with a substantially reduced amount of contrast material and thus, might decrease the risk of CIN and enable TACE for patients with renal impairment. Furthermore, 4D-CTA decreases operator radiation exposure during intervention and increases diagnostic confidence in the exclusion of portal vein thrombosis. We therefore lend countenance to a more widespread use of 4D-CTA for guiding TACE, but further research is warranted to optimize and refine this technique. 


\section{Conflict of Interest}

'Moritz H. Albrecht received a speaker fee from Siemens. Julian L. Wichmann received speaker fees from Siemens and General Electric. Ralf W. Bauer received speaker fees from and was a consultant for Siemens.'

\section{Widmung}

This manuscript is dedicated to our mentor Professor Thomas J. Vogl on his 60th birthday. Dieses Manuskript ist unserem Mentor Professor Thomas J. Vogl zum 60. Geburtstag gewidmet.

\section{References}

[1] Bonekamp S, Jolepalem P, Lazo M et al. Hepatocellular Carcinoma: Response to TACE Assessed with Semiautomated Volumetric and Functional Analysis of Diffusion-weighted and Contrast-enhanced MR Imaging Data. Radiology 2011; 260: $752-761$

[2] Bouvier A, Ozenne V, Aubé C et al. Transarterial chemoembolisation: effect of selectivity on tolerance, tumour response and survival. Eur Radiol 2011; 21: 1719-1726

[3] VogI T], Kreutzträger M, Gruber-Rouh T et al. Neoadjuvant TACE before laser induced thermotherapy (LITT) in the treatment of non-colorectal non-breast cancer liver metastases: feasibility and survival rates. Eur J Radiol 2014; 83: $1804-1810$

[4] Vogl T], Naguib NNN, Nour-Eldin N-EA et al. Review on transarterial chemoembolization in hepatocellular carcinoma: Palliative, combined, neoadjuvant, bridging, and symptomatic indications. Eur J Radiol 2009; 72: $505-516$

[5] Vogl T], Zangos S, Eichler K et al. Colorectal liver metastases: regional chemotherapy via transarterial chemoembolization (TACE) and hepatic chemoperfusion: an update. Eur Radiol 2006; 17: 1025-1034

[6] Chapman WC, Majella DoyleMB, Stuart JE et al. Outcomes of neoadjuvant transarterial chemoembolization to downstage hepatocellular carcinoma before liver transplantation. Ann Surg 2008; 248: 617-625

[7] Eichler K, Jakobi S, Gruber-Rouh T et al. Transarterial chemoembolisation (TACE) with gemcitabine: phase II study in patients with liver metastases of breast cancer. Eur J Radiol 2013; 82: e816-e822

[8] Heckman JT, deVera MB, Marsh JW et al. Bridging Locoregional Therapy for Hepatocellular Carcinoma Prior to Liver Transplantation. Ann Surg Oncol 2008; 15: 3169-3177

[9] Vogl T], Müller PK, Mack MG et al. Liver metastases: interventional therapeutic techniques and results, state of the art. Eur Radiol 1999; 9: $675-684$

[10] King JN, Champlin AM, Kelsey CA et al. Using a sterile disposable protective surgical drape for reduction of radiation exposure to interventionalists. Am J Roentgenol 2002; 178: 153-157
[11] Santen CB, Kan K, Velthuyse HJ et al. Exposure of the radiologist to scattered radiation during angiography. Radiology 1975; 115: 447-450

[12] Hayakawa K, Tanikake M, Kirishima T et al. The incidence of contrastinduced nephropathy (CIN) following transarterial chemoembolisation (TACE) in patients with hepatocellular carcinoma (HCC). Eur Radiol 2014; 24: $1105-1111$

[13] Yamazaki H, Oi H, Matsushita M et al. Renal cortical retention on delayed CT and nephropathy following transcatheter arterial chemoembolisation. Br J Radiol 2001; 74: 695-700

[14] Zhou C, Wang R, Ding $Y$ et al. Prognostic factors for acute kidney injury following transarterial chemoembolization in patients with hepatocellular carcinoma. Int J Clin Exp Pathol 2014; 7: 2579-2586

[15] Bartorelli AL, Marenzi G. Contrast-Induced Nephropathy. J Interv Cardiol 2008; 21: 74-85

[16] Bucher AM, De Cecco CN, Schoepf U] et al. Is contrast medium osmolality a causal factor for contrast-induced nephropathy? Biomed Res Int 2014; 2014: 931413

[17] Gleeson TG, Bulugahapitiya S. Contrast-Induced Nephropathy. Am J Roentgenol 2004; 183: 1673-1689

[18] Persson PB. Contrast-induced nephropathy. Eur Radiol 2005; 15 (Suppl. 4): D65-D69

[19] Chou S-H, Wang Z], Kuo J et al. Persistent renal enhancement after intraarterial versus intravenous iodixanol administration. Eur ] Radiol 2011; 80: $378-386$

[20] Davenport MS, Khalatbari S, Cohan RH et al. Contrast material-induced nephrotoxicity and intravenous low-osmolality iodinated contrast material: risk stratification by using estimated glomerular filtration rate. Radiology 2013; 268: 719-728

[21] Nyman U, Almén T, Jacobsson B et al. Are intravenous injections of contrast media really less nephrotoxic than intra-arterial injections? Eur Radiol 2012; 22: 1366 - 1371

[22] Lufft V, Hoogestraat-Lufft L, Fels LM et al. Contrast media nephropathy: intravenous $\mathrm{CT}$ angiography versus intraarterial digital subtraction angiography in renal artery stenosis: a prospective randomized trial. Am J Kidney Dis 2002; 40: 236-242

[23] Chou S-H, Wang Z], Kuo J et al. Persistent renal enhancement after intraarterial versus intravenous iodixanol administration. Eur J Radiol 2011; 80: $378-386$

[24] Schernthaner RE, Duran R, Chapiro ] et al. A new angiographic imaging platform reduces radiation exposure for patients with liver cancer treated with transarterial chemoembolization. Eur Radiol 2015; 25: 3255-3262

[25] Meinel FG, Nikolaou K, Weidenhagen R et al. Time-resolved CT angiography in aortic dissection. Eur ] Radiol 2012; 81: 3254-3261

[26] Sommer WH, Becker CR, Haack M et al. Time-resolved CT angiography for the detection and classification of endoleaks. Radiology 2012; 263: 917-926 